http://revistas.uchile.cl/index.php/RU/index

\title{
EI siglo XXI y el automóvil
}

The twenty-first century and the automobile

Juan Parrochia Beguin [1978]

\section{Filiación}

Profesor Titular de la F.A.U. Universidad de Chile.

\section{Resumen}

Reflexiones de J. Parrochia B. sobre el automóvil frente al agotamiento de la energía tradicional, la defensa del medio ambiente, la protección a la integridad y vida humana, la competencia de otros medios de transporte y el devenir de este vehículo en el siglo XXI.

\section{Palabras Claves}

Transporte siglo XXI, vehículos motorizados, defensa del medio ambiente.

\begin{abstract}
Reflections by J. Parrochia B. with respect to the vehicle from the depletion of traditional energy, protection of the environment, protection of human life and limb, competition from other modes of transport and the future of this vehicle in the XXI century.
\end{abstract}

\section{Key Words}

21st Century transportation, motor vehicles, protecting the environment.

\section{Sumario}

El agotamiento de la energía tradicional

Defensa del Medio Ambiente

Protección a la integridad y vida humana

Competencia de otros medios de transporte

El automóvil del siglo XXI

El automóvil enfrenta, desde hace algunos años, fuertes presiones que lo forzarán a adaptarse a un nuevo conjunto de valores y a definir la orientación y cambios que tendrá que absorber, para poder enfrentar con éxito el transporte individual del siglo XXI.

Nacido en la postrimería del siglo XIX, no ha tenido innovaciones de fondo, prácticamente, desde 1914. Sin embargo no podrá sobrevivir al siglo XX, si no modifica profundamente algunos vicios y malos hábitos que lo han llevado a ser uno de los principales delincuentes de la sociedad humana. Amparado por sus propios miembros, es perdonado más allá de los límites tolerables, debido principalmente a los grandes intereses creados en torno a su existencia.

Las presiones sobre el automóvil provienen de varios frentes, entre los cuales se destacan cuatro fundamentales: El agotamiento de la energía tradicional, la defensa del medio ambiente, la protección de la integridad y vida humana, y la competencia de otros medios de transporte. 
El automóvil, desde su divulgación a principio del siglo XX, logró impactar a tal punto la comunidad humana, que podemos decir que con él se inicia la revolución tecnológica universal más significativa en toda la historia y prehistoria del mundo.

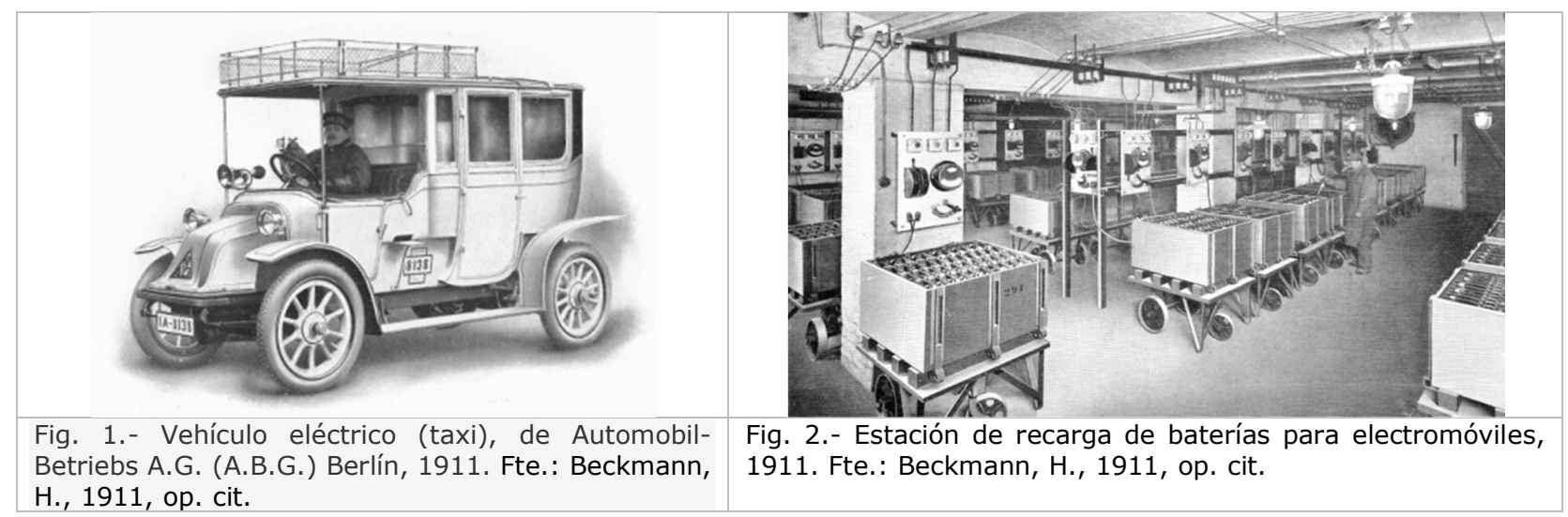

\section{El agotamiento de la energía tradicional}

El Automóvil, desde su aparición, ha usado como combustible habitual la gasolina. Es cierto que al origen, los primeros motores fueron a vapor y durante las guerras se usaron algunos substitutos. Hay también algunos automóviles que funcionan a petróleo.

Con igual facilidad, sin embargo, el automóvil funciona con gas natural. En Chile ello se usa poco, a pesar de que la adaptación al uso de gas es fácil y económica. El rendimiento del gas como combustible para automóvil es bastante alto y se puede estimar que el costo por kilómetro recorrido se reduce a la mitad e inclusive al tercio, con respecto al del combustible tradicional.

Chile tiene una gran reserva de gas y es factible que ese gas pueda ser utilizado por los automóviles durante gran parte del siglo XXI.

Por otra parte, en el mundo existe todavía una gran reserva de carbón, mucho más amplia que la de petróleo. En la medida en que el precio del petróleo aumente, será cada día más factible económicamente explotar la transformación del carbón en gasolina sintética.

Chile también cuenta con amplias reservas de turba en Magallanes, y carbones más antiguos en toda la zona Sur, especialmente en Malleco, Arauco y Concepción. Si bien es factible que este combustible resulte algo caro, será también una de las más probables fuentes de energía del automóvil del siglo XXI.

La propia gasolina existirá aún en los primeros decenios del siglo XXI, con relativa abundancia. Lo más probable es que ella sea mezclada con combustibles sintéticos de menor calidad, en forma progresiva durante un largo período. 
Si bien los nuevos descubrimientos y yacimientos de petróleo con más lentos que el aumento de los consumos mundiales, es posible contar, con objetividad, con una cierta disminución de la tasa de crecimiento de dichos consumos, si no de una disminución de él.

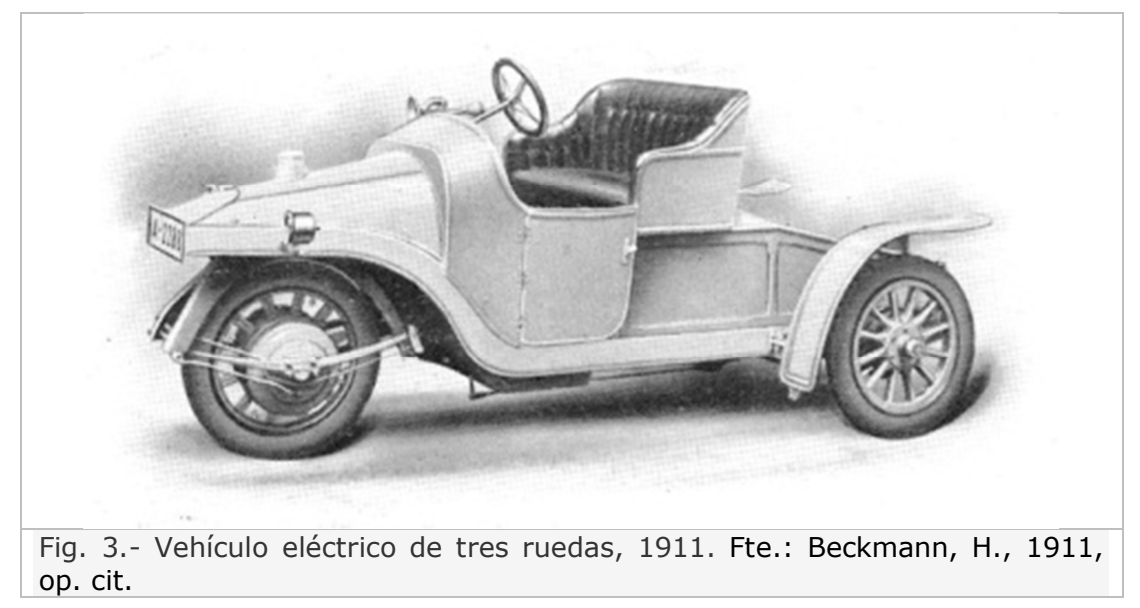

No cabe duda que la energía se malgasta hoy en forma exagerada y sin beneficio para nadie. Es razonable, según estudios hechos en la materia, deducir 20 a $25 \%$ del consumo de energía sólo por el hecho de su mejor aprovechamiento, o sea, sin disminuir en nada el nivel de vida, ni el bienestar.

Por otra parte, una búsqueda de una vida más biológica y menos maquinista puede llevarnos a otras importantes economías inesperadas.

Estas economías de energía pueden representar en los próximos años, más recursos energéticos que los que se pueden esperar de los primeros años de las industrias de combustibles sintéticos de reemplazo y pueden significar el puente que permita lograr, sin crisis violenta, el nuevo equilibrio energético.

Según lo que se aprecia, el petróleo duplicará su valor en los próximos 12 a 18 años. Es posible que se cuadruplique su valor para el año 2010.

La inercia de las industrias de automóviles en modificar sus esquemas de fabricación, la rutina de los usuarios de los automóviles, los grandes intereses atados a todo proceso manufacturero, a la distribución y al mantenimiento, sumados a los grandes intereses de la extracción e industria del petróleo, y los ligados a las materias primas como el cemento y el acero, que son los grandes insumos de las infraestructuras y de los vehículos, hacen que el problema se arrastre sin que se encuentren las soluciones satisfactorias de substitución que el problema requiere.

La energía nuclear no se ve como recurso claro de substitución de tracción para el automóvil. En primer lugar, las actuales reservas de substancias radioactivas son más limitadas que las del petróleo, y en segundo lugar, existen serias resistencias ecológicas de parte de la población para usar estar energía en general. Su costo, por lo demás, es bastante alto. 
La energía eléctrica puede también ser usada por los automóviles, ya sea acumulándola en batería, ya sea alimentando los vehículos directamente a través de la pista o de las barreras. Si bien esta energía tiene una ventaja complementaria, dado su limpieza, su validez reside en que ella provenga de fuentes productoras renovables y no de la combustión de petróleo o carbones porque ello sería solamente trasladar el problema de lugar. Lamentablemente la reserva de fuentes renovables de energía eléctrica es también muy limitada. Chile no tiene actualmente grandes limitaciones a este respecto, pero sus recursos estarán pronto en su máxima posibilidad y las reservas de que dispone, en la región de Aysén, no son aún económicamente trasladables a los grandes centros de consumo. Para el siglo XXI es posible encontrar manera de resolver ese traslado, pero seguramente él será absorbido por las necesidades generales de energía del país.

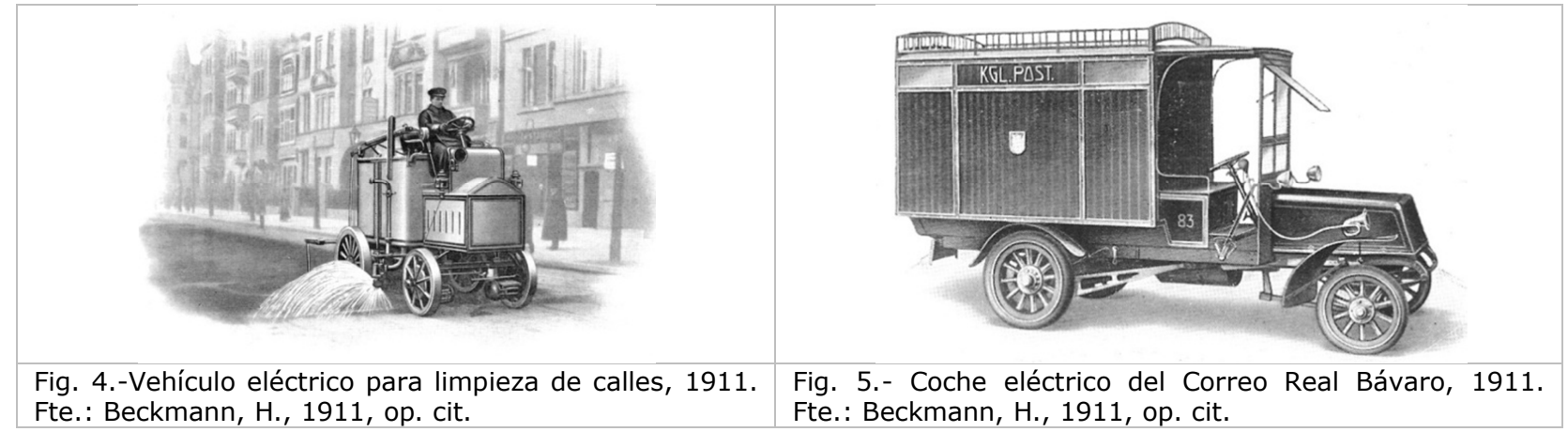

La búsqueda de combustibles sintéticos está encaminada fundamentalmente a los más competitivos y a los que puedan ser usados como substitutos sin cambiar los motores y vehículos en general. Ellos, con toda seguridad, reemplazarán la gasolina por un largo período del siglo XXI, parcialmente al inicio para, poco a poco, llegar al total.

El metanol está ya listo para ser fabricado y se podrá agregar en 12 a $15 \%$ al combustible tradicional. Es hoy aún algo caro, pero en los próximos 20 años estará en precio competitivo. El metanol se fabrica de desechos orgánicos, especialmente de la madera del carbón, de la basura urbana y de los desechos agrícolas.

Más trascendente es, sin embargo, llegar a la licuación del carbón y a la obtención del "Syncrude". Si el carbón se puede lograr a precios de 10 dólares la tonelada en el mercado internacional, será una de las soluciones económicamente aceptables para obtener combustibles en el siglo XXI.

Las reservas de carbón están repartidas en grandes extensiones en Europa, Asia, Africa y América, y ellas son diez veces superiores en cantidad a las de petróleo. Para el siglo XXI, sin embargo, uno de los problemas marginales que existirá será el de obtener mineros para extraer el carbón y si él no se puede obtener a cielo abierto, seguramente habrá dificultades y fuertes aumentos de costos.

La búsqueda de combustibles de reemplazo para los motores a explosión de los automóviles, seguramente logrará pronto su objetivo en forma económica y abundante. Se invertirán inmensos recursos para instalar las nuevas industrias correspondientes, a partir de ahora. 
Hacen falta más de 20 años para montarlas, teniendo en cuenta su enorme volumen físico y su enorme inversión monetaria. Se estima que ya para los primeros años del siglo XXI, serán necesarios en el mundo, 200 millones de toneladas anuales de carburantes sintéticos para mezclarlos, en dosis de más o menos $10 \%$, con los carburantes naturales.

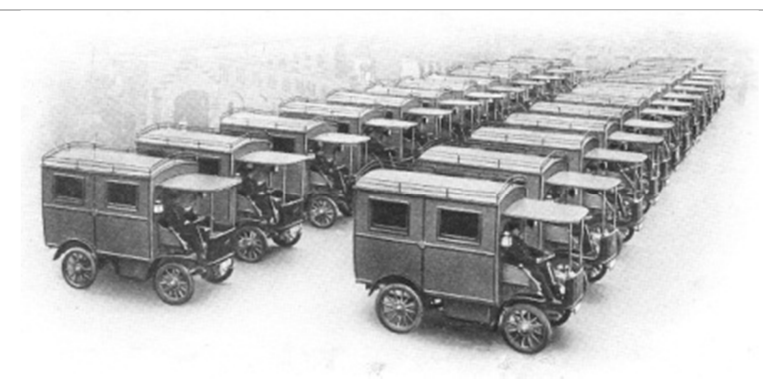

Fig. 6.- Coches eléctricos del Correo Imperial Alemán, Berlín, 1911. Fte.: Beckmann, H., 1911, op. cit.

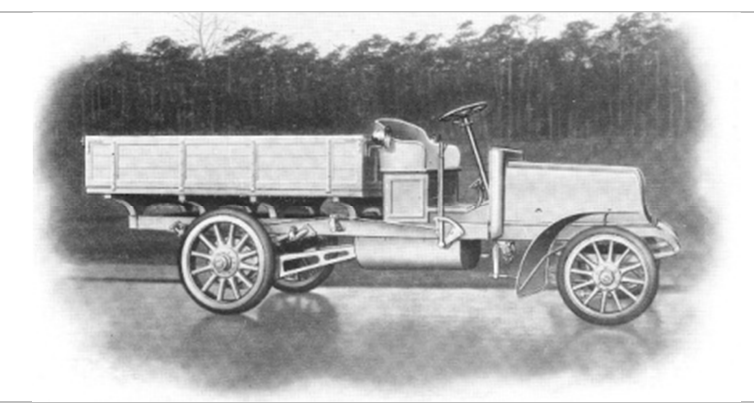

Fig. 7.- Camión eléctrico para transporte de cargas de 3 toneladas, 1911. Fte.: Beckmann, H., 1911, op. cit.

Si consideramos que para cada millón de toneladas anuales es necesario invertir aproximadamente 50 millones de dólares sólo para la producción y refinación del carburante sintético, sin contar las inversiones necesarias para la extracción de la materia prima y los transportes, se pueden apreciar los estratosféricos capitales necesarios a la partida. Estos irán aumentando en el transcurso del siglo XXI al ir reemplazando, cada vez en mayor proporción, los derivados del petróleo.

Existen también otros combustibles sintéticos factibles de ser usados en etapas más avanzadas del siglo XXI. Entre ellos se cuenta el Hidrógeno y el Amonía, cuyo costo actual de obtención supera el de los derivados del carbón. La ventaja de estos combustibles radica en que se obtienen del agua y del aire respectivamente y dichos elementos están presentes en todos los lugares del mundo.

En la línea de otras energías, que no corresponda a carburantes sintéticos, existen serias investigaciones en lo que respecta al antiguo vapor de agua y a las energías solares y eólicas. Sin embargo, estas últimas energías, ya sean utilizadas en forma directa o previa transformación en energía eléctrica, resultan aún muy caras y falta resolver muchos problemas de su adaptación eficiente en el automóvil. Posiblemente estas energías serán usadas, a mediados del siglo XXI, en forma masiva en estos vehículos.

Desde el punto de la energía, el automóvil al inicio del siglo XXI, tendrá la tendencia a mantenerse con poca variación con respecto a su versión actual. Seguramente se le incorporará una cierta versatilidad para el consumo de diferentes combustibles naturales y sintéticos. Los motores serán más económicos y tendrán un mayor rendimiento. Los vehículos serán alivianados con igual propósito y sus velocidades serán seguramente limitadas a los niveles más rentables, de 60 a $80 \mathrm{~km} /$ hora, en las ciudades.

Existirán automóviles diversificados, para centros urbanos de actividad intensa, para ciudades y para viajes de mediana distancia. 


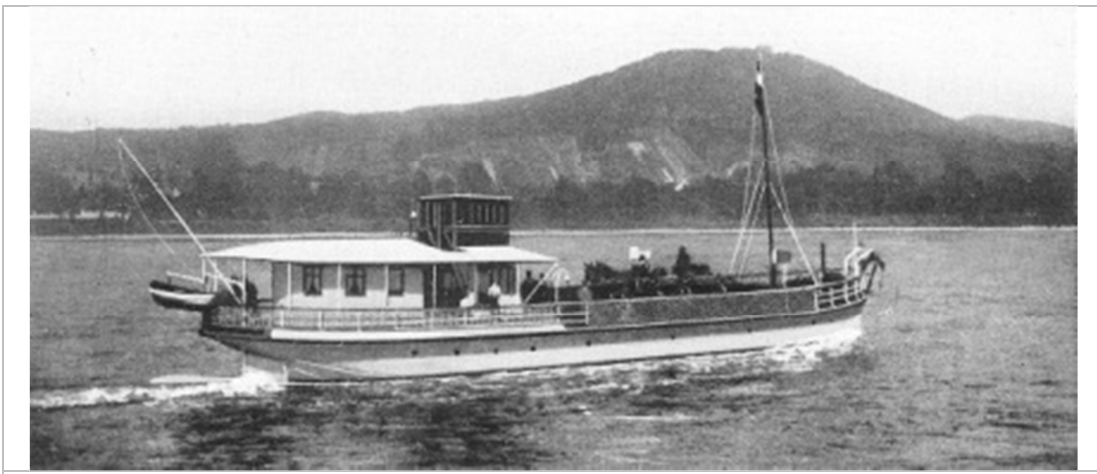

Fig. 8.- Ferry acumulador en el Rin, 1911. Fte.: Beckmann, H., 1911, op. cit.

Los viajes a largo distancia ya no se realizarán en automóviles y éstos serán transportados junto con sus conductores. Sólo con propósito deportivo se realizarán largos recorridos y grandes velocidades.

En el siglo XXI se llevarán a cabo ensayos de transportes de automóviles en cadena, ya sea dando movimiento a la infraestructura, ya sea montándolos sobre plataformas. Con este sistema se logrará mantener la ilusión de un transporte individual y se resolverán algunos puntos de gran congestión, devolviendo la individualidad una vez superados.

Se verán muchos inventos en lo que respecta al automóvil, sin embargo, muy pocos de esos inventos pasarán a tener un uso masivo en el mundo.

\section{Defensa del Medio ambiente}

Desde principios del siglo XX se empieza a poner en duda que el ruido, el humo, los gases, la falta de sol y el polvo sean síntomas de progreso, trabajo, industrialización, poder y riqueza. Se empiezan a revisar los ya anticuados conceptos del período Maquinista, que aún hoy perduran con mucha fuerza en la población, y que vinieron a desbalancear el equilibrio armónico entre el hombre y la naturaleza.

Durante miles de años el hombre no había intentado fabricar en serie ninguna de sus invenciones $y$, por lo tanto, no ponía en real peligro la existencia de los otros seres vivos animales o vegetales, ni variaban sensiblemente las estructuras geológicas, ni las composiciones, ni las proporciones de los elementos naturales.

Las primeras destrucciones sistemáticas del medio ambiente, sin embargo, remontan a varios siglos atrás en Europa, Africa del Norte, Asia Menos, América del Norte y del Sur y China, cuando el Hombre destruyó grandes extensiones de suelo por cultivos inadecuados y erosión.

La menor cantidad de habitantes, su menor conocimiento de las técnicas, su menor afán de lucro, su menor ansia de dominio, su menor poder de destrucción, etc., habían permitido que los ciclos naturales borraran una y otra vez las desastrosas huellas de los hombres y restituyeran el orden de la naturaleza. 
El automóvil es, seguramente, el individuo de la fauna mecánica más numeroso en el mundo actual. El daño que él produce en el medio ambiente, si bien no es muy importante individualmente considerado, al multiplicarse por millones y billones se transforma en un monstruo infernal.
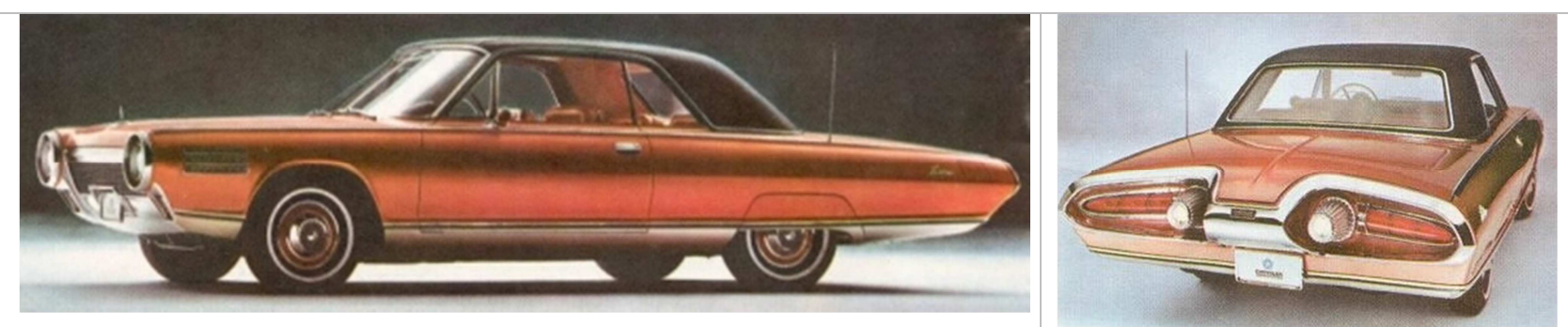

Figs. 9 y 10.- Automóvil Chrysler con turbina de gas, Detroit, Michigan, en 1963. Fte.:http://www.motorspain.com

\begin{tabular}{|c|c|c|c|}
\hline & \multicolumn{2}{|c|}{$\begin{array}{l}\text { VEHICULOS EN EL MUNDO } 1975 \\
\text { (en millones de vehículos) }\end{array}$} & \multirow[b]{2}{*}{ CAMIONES } \\
\hline & TOTAL & $\begin{array}{l}\text { AUTOMOVILES } \\
\text { Y OTROS }\end{array}$ & \\
\hline América del Norte & 140,8 & 113,4 & 27,7 \\
\hline Europa Occidental & 95,7 & 85,4 & 10,4 \\
\hline Oceanía & 8,1 & 6,4 & 1,7 \\
\hline Extremo Oriente & 31,0 & 18,9 & 12,2 \\
\hline Europa Oriental & 14,3 & 8,4 & 5,9 \\
\hline América del Sur y Central & 15,3 & 11,0 & 4,3 \\
\hline África & 6,0 & 4,1 & 1,9 \\
\hline Cercano Oriente & 2,7 & 1,7 & 1,0 \\
\hline Zona del Caribe & 1,4 & 1,1 & 0,3 \\
\hline República Popular China & 0,7 & 0,04 & 0,7 \\
\hline
\end{tabular}

(Informe CEPAL)

CRECIMIENTO VEHICULOS MOTORIZADOS ENTRE 1964-1973

\begin{tabular}{lr} 
& \multicolumn{1}{c}{$\%$} \\
Africa & \\
Asia & 58,0 \\
Europa & 291,0 \\
Norte América & 99,0 \\
Oceanía & 47,0 \\
Sudamérica & 62,0 \\
& 143,0
\end{tabular}

("Ingeniería del Tránsito", Álvarez)

El parque automotriz en el mundo es uno de los principales contaminadores del medio ambiente, en sus aspectos olfativo, auditivo y visual.

8 


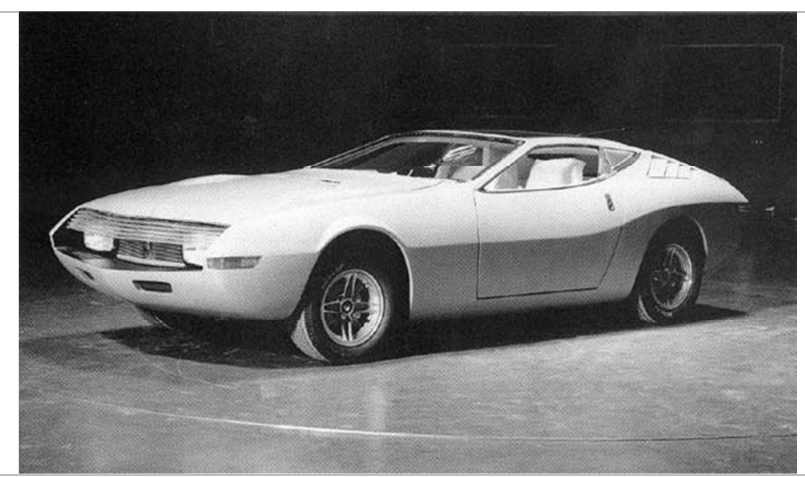

Fig. 11.- Prototipo Modelo Toyota EX-I, 1969. Toyota, 1970, op. cit.

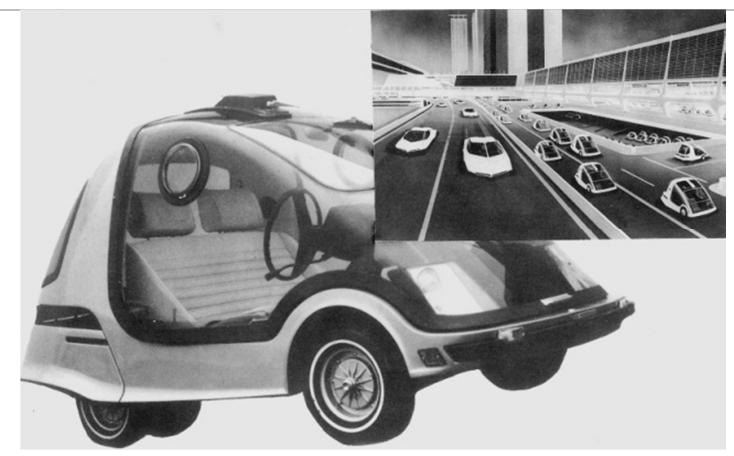

Fig. 12.- Prototipo Modelo Toyota EX-II, 1969. Toyota, 1970, op. cit.

Del punto de vista olfativo, los automóviles emiten gases tóxicos y no tóxicos, provenientes de la combustión más o menos completa de los carburantes que consumen y de los aceites que utilizan. Crean polvo por el roce de sus ruedas sobre el pavimento y la tierra. Todo ello, con el aire y con la humedad, se transforma en una atmósfera tóxica y sucia que ataca el sistema respiratorio de los seres vivos y también el sistema circulatorio y renal, sin perjuicio de otras consecuencias derivadas a todo el organismo. Por otra parte, estas impurezas destruyen y ensucian los objetos y los edificios urbanos y rurales a lo largo de las calles y caminos, produciendo un importante gasto de recursos muy pocas veces contabilizado.

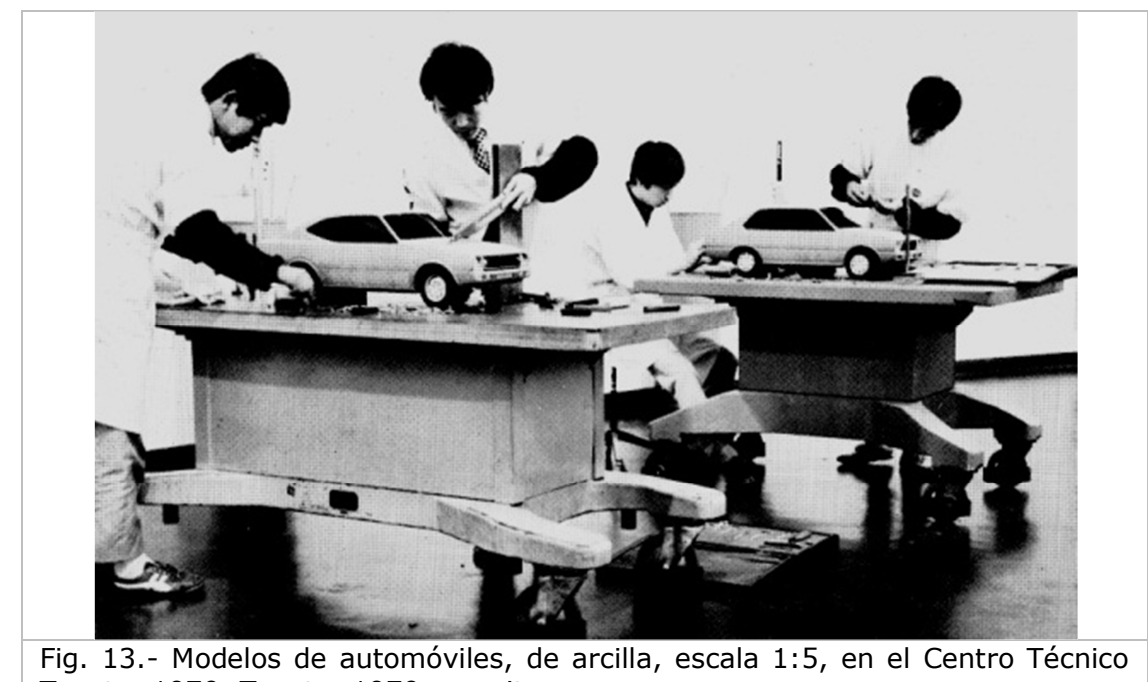

Toyota, 1970. Toyota, 1970, op. cit.

Del punto de vista auditivo, el automóvil contamina el ambiente con una gran gama de ruidos, más o menos intensos y molestos, entre los cuales se cuentan fundamentalmente el ruido del motor, el chirrido de los frenos, el crujir de la carrocería, el soplido del acelerador, el retumbar de la bocina, el sonido del escape, el roce de los neumáticos, el golpe de los choques y algunos otros. Todos ellos juntos conforman un ambiente insoportable para el trabajo, el dormir, el 
descanso, la recreación, el estudio, etc., dañando fuertemente el sistema nervioso de los seres vivos y causando otros males derivados a todo el organismo.

Del punto de vista visual, el automóvil contamina el medio ambiente también debido a su abundancia. Los estacionamientos en las calles, avenidas y parques impiden ver el paisaje urbano y apreciar la arquitectura.

Por otra parte, proliferan las playas de estacionamiento en terrenos urbanos, dado que es mejor negocio tener una playa que un edificio. Aquellas dan más renta, pagan menos impuestos y necesitan menos inversión que ningún otro tipo de negocio. Por ese concepto se destruyen las fachadas de las calles y los edificios de las áreas centrales. Por todas partes se pierde el equilibrio del medio y proliferan el desorden y la anarquía en el espacio que rodea al ser humano, aumentando aún más el polvo y la contaminación. Por último no debemos olvidar la falta de tranquilidad del cuadro urbano y su movimiento permanente que irritan en forma continua la retina del transeúnte y del observador, tanto por su movilidad como por su brillo. Esta contaminación también afecta al sistema nervioso de los seres vivos e impide el normal desarrollo de las funciones vitales.

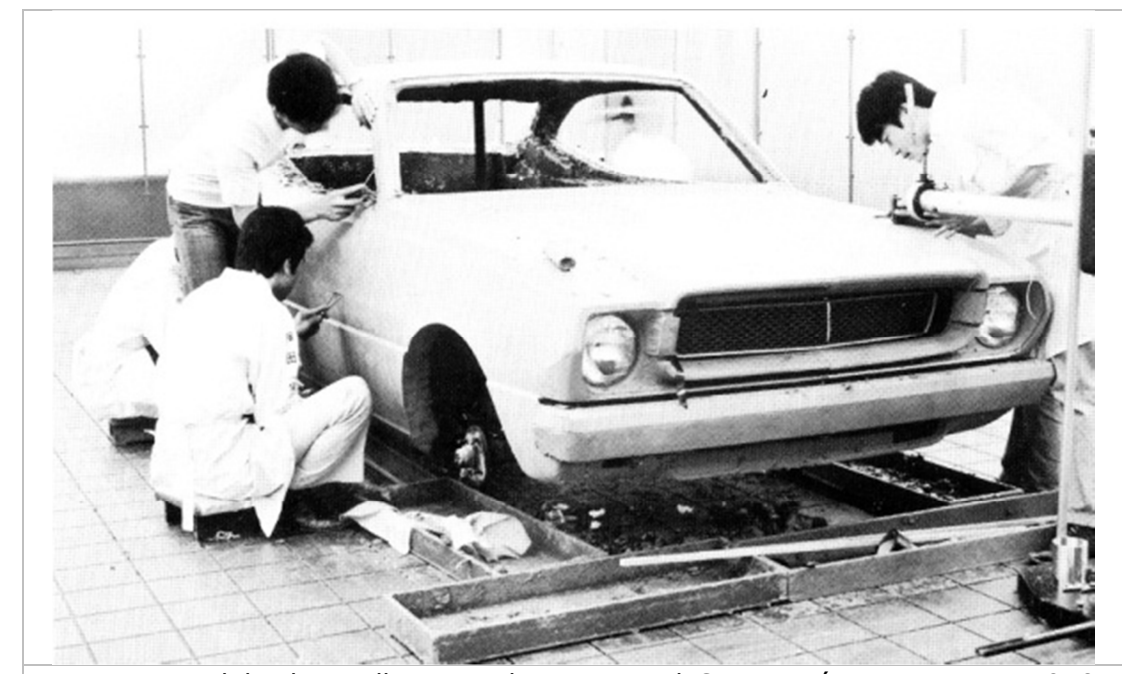

Fig. 14.- Modelo de arcilla a escala 1:1, en el Centro Técnico Toyota, 1970. Toyota, 1970, op. cit.

Frente a este deterioro del medio ambiente, sólo en los últimos años la opinión pública ha ido tomando conciencia de este fenómeno progresivo. Pero, aún hoy, ni los industriales ni los distribuidores han tenido interés en abordar este problema en los vehículos que fabrican o distribuyen. Por otra parte, las autoridades de ningún país del mundo han querido, ni sabido, tomas medidas electivas para evitar esta sistemática destrucción del medio ambiente y proteger la población y el aire que respiran.

Muchos intereses creados alrededor del automóvil, tal como hoy existe, están encadenados, impidiendo una revisión de fondo de este problema. 
El motor a explosión no garantiza un $100 \%$ de eficiencia en la combustión del carburante y a medida que el motor envejece, este problema se hace cada vez más crítico.

La búsqueda de un nuevo tipo de motor significa también un cambio en la fuente de energía y esto obliga al abandono del petróleo y sus derivados en torno a los cuales gira un inmenso imperio económico que no está dispuesto a quedar fuera de la partida.

Los nuevos tipos de motores se irán buscando con mucha tranquilidad $y$, si bien experimentalmente habrá varios resueltos a fines del siglo $\mathrm{XX}$, no estarán aún en condiciones de ser fabricados, ni usados masivamente y sus costos serán aún muy altos.

Sólo a mediados del siglo XXI empezarán a circular masivamente estos nuevos automóviles con energías naturales, no contaminantes del medio ambiente, sin emitir gases tóxicos, sin ruidos molestos y habiéndose, por fin, resuelto sus estacionamientos en lugares discretos.

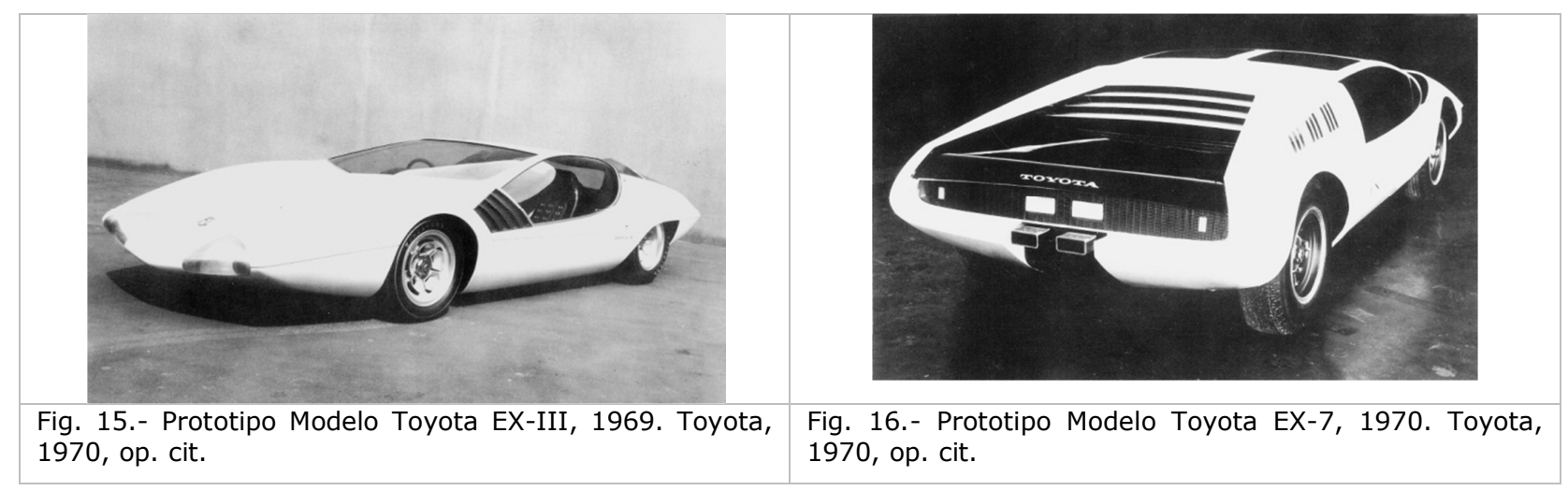

Las investigaciones están ya muy avanzadas y pronto aparecerán en el mercado, pero no en forma masiva, los automóviles con motores eléctricos con energía acumulada en potentes baterías que se enchufarán después de cada viaje, ya sea en el trabajo o en la residencia. Para mayores itinerarios se podrá hacer recambio de baterías en los servicentros. Aparecerán los vehículos con tema-corriente, ya sea en las pitas en forma directa, ya sea por inducción o en forma magnética.

Aparecerán también los vehículos con motores nucleares, los motores solares, los motores eólicos y otros, ya sea usando directamente las energías o transformándolas previamente en energía eléctrica. 


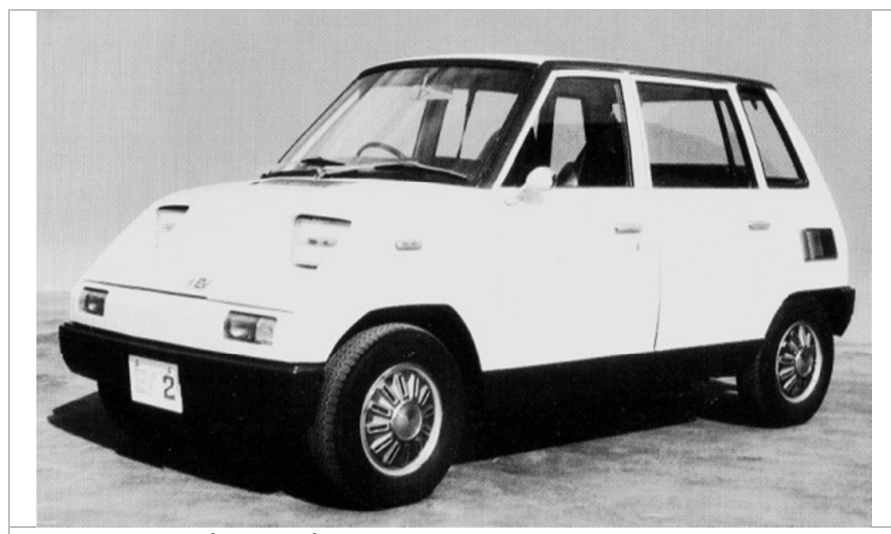

Fig. 17.- Vehículo eléctrico Toyota (EV2) 1970. Toyota, 1970, op. cit.

En una línea paralela de desarrollo, las bicicletas y triciclos evolucionarán en el aprovechamiento de la energía humana, del conductor y de sus pasajeros, complementada con la aceleración de gravedad, las cuales serán acumuladas con ingeniosos sistema de volantes y engranajes. Estos artefactos de muy esbelta construcción y con características similares al automóvil en la individualidad de su transporte, ocuparán un importante lugar en los vehículos de barrios y de centros urbanos. Ellos presentarán ventajas por su peso, su volumen, su costo, la facilidad de estacionamiento, lo sano de su ejercicio, su no contaminación, su economía de energía, se velocidad sin peligro, etc.

Existe conveniencia y urgencia en modificar el actual y delictivo automóvil por un artefacto no contaminante del medio ambiente, y en evitar todo el daño que se hace a los seres vivos y especialmente al hombre. Los intereses creados, en torno al mantenimiento de la situación actual y de su prolongación hasta las últimas consecuencias, harán muy lenta y difícil la implantación de nuevos automóviles que puedan coexistir dentro de la naturaleza sin dañarla.

A pesar de que hace un siglo se hizo funcionar el primer vehículo eléctrico, y de que el primer vehículo que alcanzó la velocidad de $100 \mathrm{~km} /$ hora, también fue un automóvil eléctrico, a principio de los 1900, no hay gran interés por parte de los productores, ni de las autoridades para promover este tipo de vehículo. Es cierto que el proceso se ha acelerado en los últimos 10 años. Desde 1974 existen minibuses eléctricos fabricados por OTIS en los Estados Unidos. Cerca de Dusseldorf, en Alemania, existe una línea de autobuses eléctricos. También han aparecido pequeñas camionetas y motos eléctricas que los próximos 10 años abundarán en los centros urbanos.

De cualquier modo, a pesar de la lentitud del proceso, en los próximos 15 a 20 años el automóvil eléctrico será competitivo con el automóvil tradicional. Se estima que a principios del siglo XXI, aproximadamente un $10 \%$ de los vehículos urbanos serán de tipo eléctrico.

El avanzado desarrollo de la Electroquímica, especialmente en lo referente a la pila de combustibles Hidrógeno-Aire, el generador Aire-Zinc, los acumuladores Socio-Azufre y ZincNíquel, hace prever para el próximo decenio una clara definición de las características del automóvil eléctrico. Este logrará una autonomía de más o menos $250 \mathrm{~km}$, con velocidades moderadas y notables ventajas en lo que se refiere a ruidos, seguridad y contaminación. 


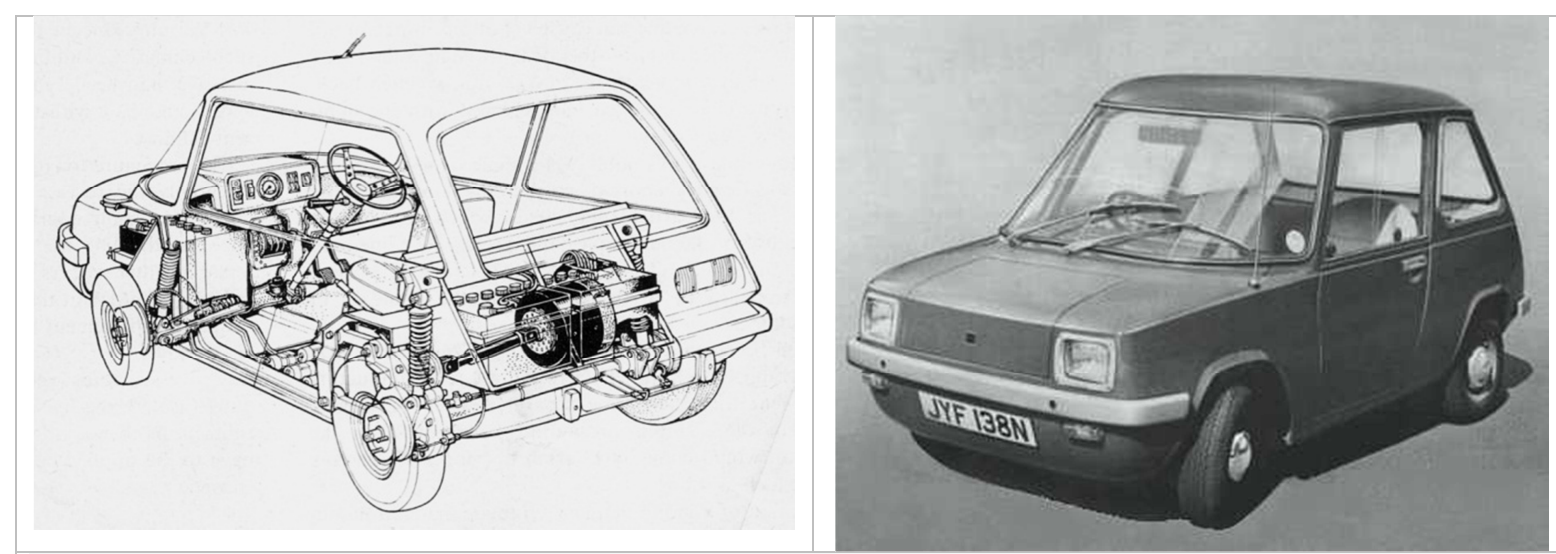

Fig. 18 y 19.- Dibujo (iz.) de la parte trasera del coche eléctrico Enfield 465 (der.), que muestra el motor eléctrico, dos baterías, transmisión y distribución interior, $60 \mathrm{~K} / \mathrm{h}$. Electrical Export Review, 1970, op. cit.

Sin embargo, realmente no se ve intento verdadero en apurar este proceso por parte de nadie. Es notorio que los grandes grupos económicos automotrices están a la expectativa de los acontecimientos y sólo actuarán en el momento oportuno para sus propios intereses, confiados en que serían ellos los únicos en disponer de los medios para lanzar dicho vehículo al mercado mundial cuando esté listo para su producción industrial en serie. Lo más probable es que las mismas industrias tengan fabricaciones mixtas de vehículos de ambos tipos durante un largo período y que así controlen el proceso de cambio.

Vemos con poco optimismo el desarrollo humanístico del futuro. Las grandes masas, las grandes necesidades, las grandes crisis, las grandes catástrofes, los grandes requerimientos, los grandes negocios y las grandes ganancias, justificarán malamente cada vez más, la crueldad social, el desprecio del individuo y el abuso del más fuerte sobre el más débil.

\section{Protección a la integridad y vida humana}

El automóvil es un vehículo que ha traído consigo una secuela de consecuencias sociales y económicas y una serie de cambios en las costumbres de los hombres y en la conformación de las ciudades más allá de toda previsión imaginable, al ser inventado a fines del siglo XIX. Sin embargo, el aspecto que realmente más resalta, por absurdo y masoquista, es su acción depredadora de la especie humana que lo creó, destruyendo vidas, causando heridos y dañando propiedades.

Es el automóvil y los vehículos motorizados, en general, la más importante causa de mortalidad de la población entre los 5 y los 60 años de edad en los países desarrollados. Los daños materiales que producen son comprables sólo con las peores catástrofes naturales y con las guerras, con el agravante que los primeros son crónicos y las últimas son, aunque críticas, sólo ocasionalmente.

Es verdad que los accidentes y las muertes ocasionadas por los carruajes en la Roma Imperial $\mathrm{y}$, posteriormente, en el moderno mundo occidental del siglo XIX fueron a tal punto 
importante, que originaron las principales normas del tránsito que hoy aplicamos. Es increíble que, a pesar de todas las inversiones realizadas por las ciudades y países en caminos y calle, en carreteras y autopistas, en puentes y túneles, en estacionamientos y edificios, en industrias y talleres, en señalización y policía, etc., se haya invertido tan poco en evitar realmente la acción de muerte y daño que esos vehículos provocan entre peatones, conductores y pasajeros por efecto de accidentes y choques.

Qué importa que la culpa sea de la máquina, del conductor o del peatón. Lo importante es la vida que se ha perdido. ¿Cuánto más pudiera hacerse para evitar que la máquina, el conductor y el peatón fueran culpables o al menos disminuyeran sus posibilidades de serlo?

¿No será, en la mayor parte de los casos, la culpa de la deficiente infraestructura, especialmente en países como el nuestro, en los cuales la inversión es increíblemente más baja que el mínimo que determina la sola conservación de las obras?

Es posible esperar que un conductor normal pueda mantener al mínima serenidad frente al desorden y lentitud exasperante del tránsito; frente a calles y avenidas cubiertas de avisos y señalizaciones, siendo las más desapercibidas las que se refieren al tráfico; frente a espectaculares infracciones y privilegios por parte de algunas personas; frente al desorden del movimiento peatonal; frente al ruido y a la contaminación del medio ambiente; frente al loteo y subdivisión increíble de las calzadas para estacionamientos y otros fines contrarios al uso de esos bienes nacionales de uso público destinados a la circulación; frente al asalto de los parásitos callejeros tanto en marcha como estacionado; frente al uso de las calles para desfiles, ferias, concentraciones, ventas, colectas, controles, etc., en cualquier día y hora; frente al maltrato y la arbitrariedad, la prepotencia y el abuso reinantes en las calzadas.

MUERTOS POR CADA 10.000 VEHICULOS MOTORIZADOS

(Cal y Mayor, y Álvarez)

$\begin{array}{llll}\text { AÑOS } & \text { USA } & \text { MEXICO } & \text { CHILE } \\ & & & \\ 1850 & 7,2 & 46,9 & \\ 1957 & 5,8 & 39,3 & \\ 1963 & 5,2 & 30,0 & 51,7 \\ 1970 & & & 36,4\end{array}$


COMPARACION ACCIDENTES DEL TRANSITO Y DELINCUENCIA EN USA-1953

(Cal y Mayor)

\begin{tabular}{|c|c|c|c|c|c|c|c|}
\hline \multicolumn{2}{|c|}{ MUERTOS } & \multicolumn{2}{|c|}{ HERIDOS } & \multicolumn{2}{|c|}{$\begin{array}{l}\text { PERDIDAS } \\
\text { ECONOMICAS }\end{array}$} & \multicolumn{2}{|c|}{ TOTALES } \\
\hline Asesinatos & $\begin{array}{l}\text { Accid. } \\
\text { Tránsito }\end{array}$ & Asaltos & $\begin{array}{l}\text { Accid. } \\
\text { Tránsito }\end{array}$ & $\begin{array}{l}\text { Robos } \\
\text { US\$ }\end{array}$ & $\begin{array}{l}\text { Accid. } \\
\text { Tránsito } \\
\text { US\$ }\end{array}$ & Delitos & $\begin{array}{l}\text { Accid. } \\
\text { Tránsito }\end{array}$ \\
\hline 7.120 & 38.800 & 92.600 & 3.350 .000 & 2.035 .770 & 3.500 .000 & 2.159 .800 & 9.900 .00 \\
\hline
\end{tabular}

\section{MUERTOS POR CADA 100 MILLONES DE VEHICULOS-MILLA EN USA}

(Cal y Mayor)

$\begin{array}{lc}\text { AÑOS } & \text { MUERTOS } \\ 1927 & 16,2 \\ 1935 & 16,5 \\ 1945 & 11,2 \\ 1950 & 7,5 \\ 1955 & 6,4 \\ 1957 & 6,0\end{array}$

En el siglo XXI nos encontrará frente a la misma situación actual, reducida, levemente, por el mayor estándar de las infraestructuras viales para vehículos y peatones, y la normal disminución porcentual que se produce por aumento del parque vehicular.

Las autopistas reducen por sus características propias, los riesgos de accidentes. Chile contará al inicio del siglo XXI, sólo con un muy reducido número de ellas en lo rural y en lo urbano.

Los transportes masivos en vía independiente como el Metro, también reducen notoriamente los riesgos de accidentes y de muerte en el tránsito general y en el de automóviles, liberando grandes áreas superficiales de la ciudad y descentralizando las zonas de actividad y de estacionamiento.

En el siglo XXI las grandes ciudades habrán seguido creciendo con igual ímpetu, a pesar de todo lo que se hable en contra de su tamaño y desproporción. Realmente a muy poca gente le importa, en el fondo, la optimización de la distribución de la población en el territorio y el tamaño de los centros poblados. Contradictoriamente, la propia regionalización permite concentrar más el poder y la economía. Los intereses nacionales a mediano y largo plazo no coinciden mucho con los intereses individuales a corto plazo.

A pesar de los romanticismos intelectuales, es poco probable que el siglo XXI traiga un mayor respeto por el ser humano y su integridad. Por el contrario, se aprecia que mientras más poblado y desarrollado deviene el Universo, más indirectas, frías e impersonales son las 
relaciones entre los hombres y menos importa el individuo, sus problemas, sus gustos y su destino.

Hoy, en la carrera de la civilización, la ciencia y la tecnología van lejos a la zaga del lucro, la supervivencia, la competencia y la especulación. Más allá aún, vienen la filosofía, la ética y el arte.

Sólo una gran crisis mundial podría modificar realmente los esquemas vigentes y reordenar los valores de la comunidad. El hombre es un símbolo económico cuyo valor está en relativa relación de equilibrio con otros símbolos más o menos significativos, según las fluctuaciones del mercado.

A pesar de todo ello, en un esquema normal de desarrollo, el siglo XXI verá introducirse un gran número de modificaciones en los automóviles y en las infraestructuras viales que derivarán en una mayor seguridad de los seres humanos circundantes y una mayor protección de sus bienes, en la medida que las grandes empresas se interesen por el aspecto comercial que presente esa seguridad y esa protección.

Sin embargo, los accidentes seguirán ocurriendo abundantemente, en menor proporción pero en mayor número, considerando el crecimiento de la población y del parque.

\section{Competencia con otros medios de transporte}

El automóvil resultó ser para el hombre una segunda piel, que lo compensó de su milenaria debilidad entre los animales de la creación. Una segunda piel que multiplicó su fuerza, su resistencia y su velocidad, y que lo transformó mágicamente en el rey de la fauna terrestre.

Sin embargo, el Universo tiene otros ámbitos en los cuales el hombre como individuo es aún un alfeñique. Desde muy antiguo, en la profundad del tiempo, el ser humano ha soñado vencer libremente, con algún medio personal, esos otros ámbitos que lo embelesan. Ha ansiado volar por el aire y las nubes, traspasar la estratósfera, nadar en las profundidades de los mares, surcar los océanos, penetrar la corteza terrestre, recorrer subterráneamente las cavernas profundas, circular por los pantanos, caminar por las altas cumbres nevadas y los hielos polares, y más lejos, recorrer los planetas y las estrellas, saltar a otras galaxias y viajar por el tiempo pasado y futuro.

El hombre envidia la velocidad de la luz, desea la eternidad de los dioses, ambiciona la fuerza de la naturaleza y ansía la infinidad del Universo.

En el siglo XXI y al igual que en el $X X$, el hombre seguirá buscando esas plumas o esas escamas que el permitirán circular como rey-pájaro o rey-pez en esos otros ámbitos. Seguramente habrá muchos descubrimientos y el automóvil sufrirá la competencia de los medios que puedan aportar una mayor versatilidad, a toda la comunidad en el ámbito inmediato, especialmente en la ciudad y en los lugares densamente habitados.

La competencia más probable al inicio, será la que venga de los medios individuales que permitan el vuelo y de los que permitan el nadar sobre y bajo el agua. Más tarde vendrán los que permitan traspasar la tierra y movilizarse en nuevos lugares de colonización en las profundidades de los mares, en los hielos antárticos y en los planetas vecinos. 


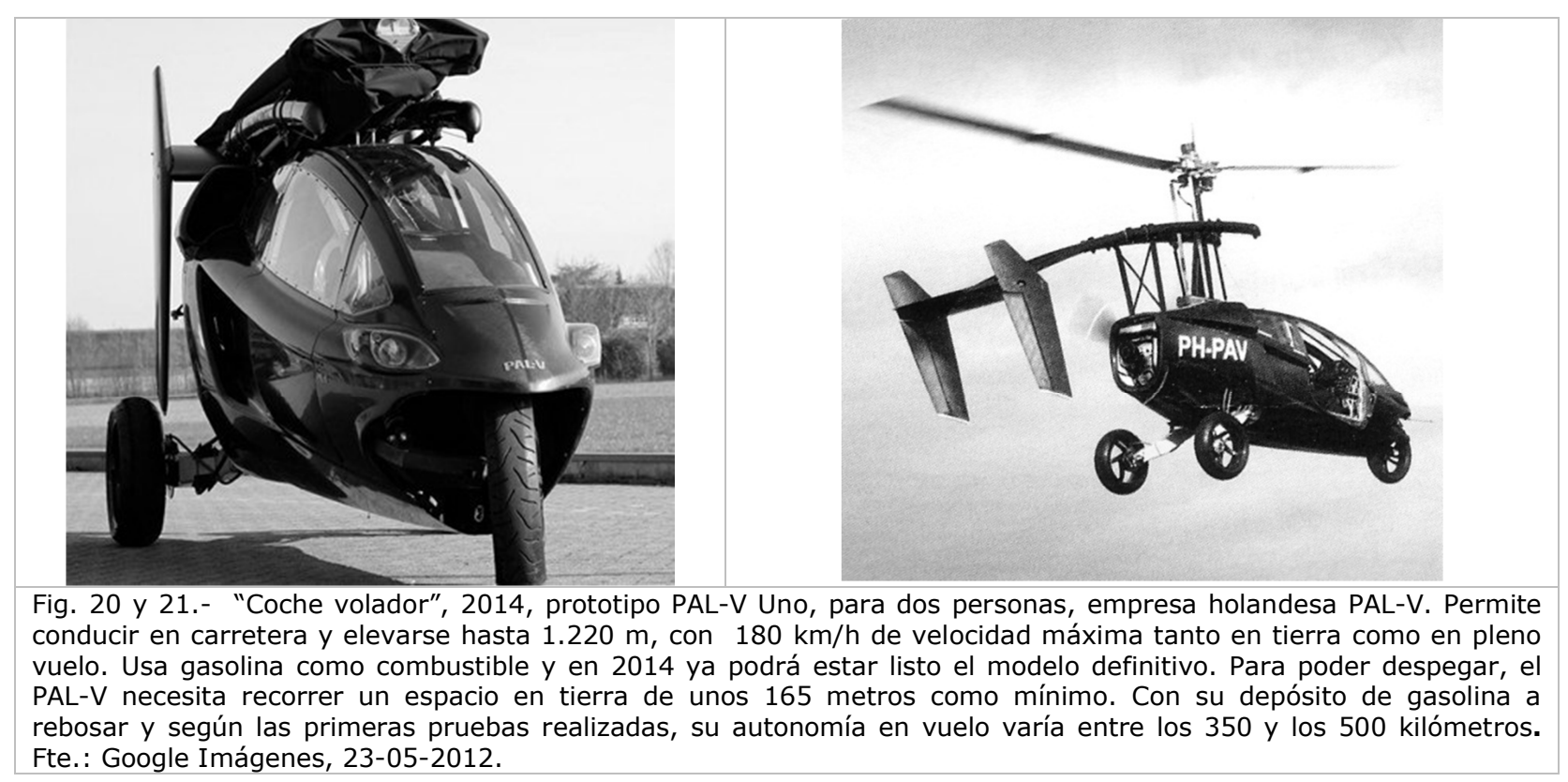

Es poco probable que al iniciarse el siglo XXI, los vuelos urbanos prosperen fácilmente y con toda libertad, en base a vehículos especiales, debido a la complejidad de usar las tres dimensiones del espacio en una reglamentación del tránsito, con la relativa dificultad en demarcarlo y señalizarlo. Por otra parte, dichos vehículos dejan desamparados a sus conductores al tocar el suelo donde el hombre mantiene su actividad principal.

Igual situación se da para los espacios tridimensionales submarinos y ambos tipos de vehículos permanecerán fundamentalmente en la categoría deportiva, exploratoria o de exhibición, durante mucho tiempo, sin lograr la categoría de vehículo de uso masivo y habitual.

Sin embargo, el automóvil sentirá el efecto de esa competencia, y aunque en proporción relativamente reducida al inicio, aparecerán los vehículos anfibios tierra-aire y tierra-agua-aire más toda una gama menor que incorporará además la nieve, el hielo, la arena, el pantano, etc.

Lo más probable es que sea el propio automóvil, que aprovechando su estructura oligopólica, sus grandes inversiones y su estructura de comercialización el que se transforme en anfibio y que se multipliquen las innovaciones tanto en su diseño, como en su propulsión, su sustentación, su energía y su estructura para lograrlo.

A mediados del siglo XXI, esta competencia y la lucha por la supervivencia, derivarán con mucha probabilidad en una nueva era de los transportes, una nueva generación irreconocible del automóvil del siglo XX, el que inclusive cambiará de nombre.

Además de la competencia antes mencionada, referente a ámbito de evolución, se perfila una competencia de parte del antiguo concurrente y uno de los predecesores del automóvil, que es el vehículo sin motor de tracción humana, el que con ciertas ventajas económicas, ambientales 
y sanitarias, seguirá siendo un rival de peligro permanente, cada vez más popular. Este vehículo también entrará en la lucha anfibia y seguramente algunas energías limpias, como el viento, las corrientes y la temperatura, vendrán a sumarse positivamente a la energía del conductor y de sus pasajeros.

Por otra parte, es indudable que en estas competencias, uno de los elementos principales será el factor económico directo, pero seguramente el determinante a la larga, resultará ser el factor económico indirecto, o sea, el correspondiente a las infraestructuras.

La superficie terrestre es la que presenta más dificultades para los transportes. El aire, el agua, el hielo, la arena, etc., permite el movimiento de vehículos con muy pocas inversiones de infraestructura. El costo de estas infraestructuras terrestres irá dañando cada vez más el futuro del automóvil, lo cual se agregará a la destrucción del medio ambiente debido a tanto pavimento impermeable, duro y brillante.

En este aspecto de la competencia no serán pocas las innovaciones que el automóvil tendrá que adoptar en lo que respecta a rodado, sustentación y suspensión. Los cojines de aire y sobre todo, la sustentación electromagnética, vendrán a liberar al automóvil de gran parte de su costosa infraestructura y, a la vez, lo harán irreconocible en el futuro. En el mismo sentido, es muy posible que el siglo XXI traiga también el resurgimiento de los canales de navegación para transitar sobre ellos en campos y ciudades, con una superficie más natural, agradable y económica.

Por último, violentas competencias vendrán, además, en tres ambientes muy difíciles de sostener para el automóvil.

En los densos centros urbanos progresarán violentamente los medios de transportes pesados o masivos que son los únicos que podrán sobrevivir en dichas áreas, por su economía de transporte, por su eficiencia y por su descontaminación ambiental.

En los centros compactos de actividad progresarán los transportes semi-individuales basados en la cinta continua, ya sea como veredas rodantes, calzadas móviles, escaladores u otros sistemas derivados del mismo principio.

En las largas y medias-largas distancias los transportes rápidos y semi-masivos en sus diferentes versiones de tierra, agua y aire, desplazarán toda posibilidad de competencia por parte de los cansadores vehículos individuales.

De la competencia entre los propios automóviles, para poder sobrevivir, y de estos con otros medios de transportes individuales en el ámbito general y con los medios de transporte masivos, continuos y rápidos en los centros urbanos más densos y en las largas distancias, nacerán a mediados del siglo XXI, vehículos tan diferentes, que ello en el fondo, representará la desaparición del automóvil.

\section{El automóvil del siglo XXI}

En resumen, deducimos de los actuales datos y de las circunstancias probables que se desarrollan para fines del presente siglo, que el escenario del siglo XXI no presentará en sus primeros años grandes innovaciones notables en lo referente a los automóviles. Inclusive 
muchos de los actuales que hoy circulan por nuestras ciudades subdesarrolladas, aún andarán en gran número por las calles y caminos en el año 2000.

Sin embargo, el germen de la mutación profunda ya estará latente. Las investigaciones estarán maduras para los futuros y profundos cambios que este automóvil sufrirá con rapidez hacia la primera mitad del siglo XXI, en todos sus aspectos, hasta el punto de desaparecer como tal.

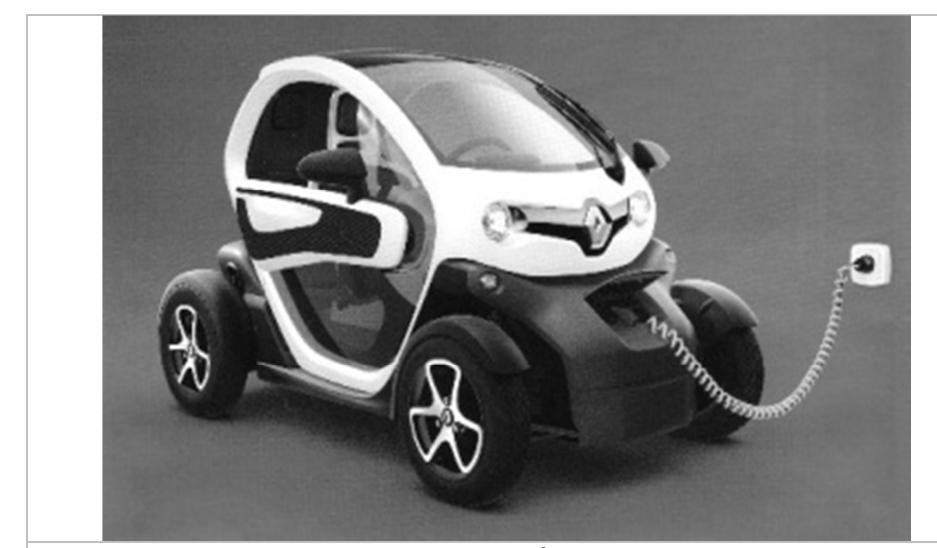

Fig. 22.- Modelo Renault Twizy, eléctrico, cero emisiones de $\mathrm{CO}_{2}$ durante su uso, salvo piezas de desgaste. Fte.: AD, 2012, op. cit.

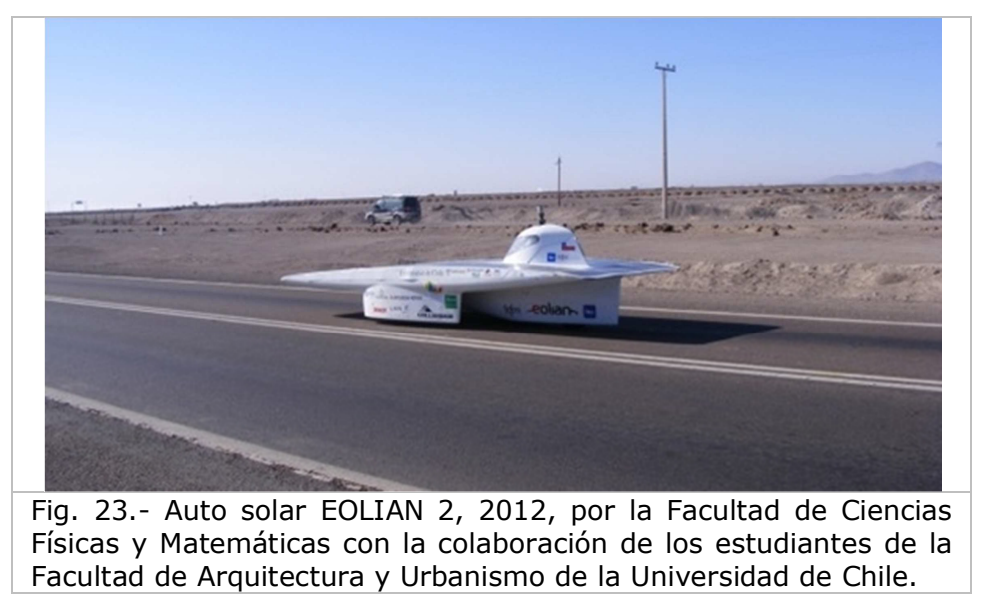

Como mariposa grácil y hermosa, el nuevo automóvil de tipo anfibio, silencioso, limpio y seguro, derivará de la defectuosa larva que es el automóvil actual y con el cual será difícil de establecer una relación de descendencia, por nuestros nietos, los habitantes de esa época.

El futuro puede y debe deparar muchos imprevistos y, lo menos probable, es que en ese mundo convulsionado se mantenga sin variar profundamente su inestable equilibrio emocional, económico, cultural, político y social.

Lo que se vislumbra a la luz de los actuales procesos puede ser una realidad, como también una ilusión. Un conflicto mundial, un cataclismo natural o una epidemia universal nos pueden

19 
devolver de un solo golpe a la más oscura etapa de nuestra prehistoria más primitiva o lanzarnos hacia adelante, ganando varios decenios de desarrollo en nuestra madurez mental o expelernos hacia el futuro lejano, envejeciendo nuestra especie y ubicándola en el umbral de su desaparición.

\section{Notas de la Redacción R.U.:}

1.- Este escrito corresponde el Documento de Trabajo N²2, DEPUR, FAU, Universidad de Chile, agosto de 1978, de circulación restringida, sin ilustraciones.

2.- Ilustrado por Revista de Urbanismo 2012, para la presente edición, a partir de:

-Catálogo, paper y otro, en archivo de M. Pavez V. - M. I. Pavez R. 2012:

-BECKMANN, H., Some Notes on the present position of the accumulator industry, Paper read before the International Electrotechnical Congres in Turin, $10^{\text {th }}$ to $17^{\text {th }}$ September $1911,25 \mathrm{p}$.

-TOYOTA, Catálogo con modelos de vehículos eléctricos y turbina de gas, 1970.

-ELECTRICAL EXPORT REVIEW, "First Comercial Electric Car. Low Running costs a feature of new British design", 1970.

-AD, Febrero, 2012.

-www.uchilefau.cl (Consulta 25-05-2012)

-Google Imágenes: http://www.motorspain.com (Consulta 25-05-2012) 